\section{Acute and post burn reconstructive surgery of the female trunk with artificial dermis to facilitate healthy pregnancy}

\author{
Dantzer $\mathrm{E}^{1 *}$, Campech $\mathbf{G}^{2}$ and Mazanovich $\mathbf{M}^{2}$
}

${ }^{1}$ Burn Center Military Instruction Hospital Sainte Anne, Toulon, France

${ }^{2}$ Rehabilitation Unit Hospital Felix Guyon Saint Denis, La Reunion, France

\section{Introduction}

The sequelae of deep and extensive burns to the abdomen can lead to serious complications during pregnancy. Studies and publications covering this subject are scarce and outdated. The complications described arise during the $3^{\text {rd }}$ trimester of pregnancy, and surgical treatments to address these complications can initiate premature labor with a risk of fetal demise. We felt it would be of interest to prevent these complications through surgical treatments performed before the pregnancy. The need to reconstruct large regions of abdominal scar tissue prompted us to turn to the Integra ${ }^{\circledR}$ dermal equivalent for preventative surgical treatments.

\section{Materials and method}

\section{Materials}

Developed in 1981 by Yannas and Burke, Integra ${ }^{\circledR}$ Dermal Regeneration Template is a bilayer composite that is made up of an extracellular matrix covered with a Silastic film [1]. This bilayer is intended to immediately and definitively cover a wound, after skin excision. The matrix is intended to act as a wound healing guide, by supporting fibrovascular growth and the regeneration of a functional dermis that shows a histologically normal architecture once the extracellular matrix has broken down. This dermal equivalent was developed by Integra Life Sciences Corporation in Plainsboro, New Jersey and is marketed under the name Integra ${ }^{\circledR}$ Dermal Regeneration Template. The composite works as a skin equivalent that has the appropriate physiological properties to perform the functions of epidermis (preventing dehydration and acting as a barrier to secondary infection), in addition to the strength and elasticity of dermis $[2,7,8]$.

The temporary epidermal layer: The superficial layer of Integra is made up of a thin film $(0.10 \mathrm{~mm})$ of polysiloxane

\begin{abstract}
More Information
*Address for Correspondence: Dantzer E, BCRM Toulon, H.I.A. Sainte Anne, 2 Boulevard Sainte Anne, BP 600, Toulon Cedex 09, France, Tel: 334162382; Email: eric.dantzer@wanadoo.fr

Submitted: 09 December, 2019

Approved: 01 May, 2020

Published: 04 May, 2020

How to cite this article: Dantzer E, Campech G, Mazanovich M. Acute and post burn reconstructive surgery of the female trunk with artificial dermis to facilitate healthy pregnancy. Arch Case Rep. 2020; 4: 028-031.

DOI: 10.29328/journal.acr.1001036

Copyright: ( 2020 Dantzer E, et al. This is an open access article distributed under the Creative Commons Attribution License, which permits unrestricted use, distribution, and reproduction in any medium, provided the original work is properly cited.

A) Check for updates

(.) OPEn ACCEss
\end{abstract}

polymer. This synthetic membrane acts as the epidermal layer of skin by controlling gas and fluid exchanges. This temporary epidermis is intended to protect the dermis while it is being revascularized (for 15 to 21 days), before being removed and replaced with an autologous epidermal graft.

The dermal layer: The dermal layer of Integra is a $1 \mathrm{~mm}$ thick matrix of bovine collagen type I and glycosaminoglycan chondroitin-6-sulfate fibers that have been cross-linked with glutaraldehyde. Various physical and chemical processes that affect $\mathrm{pH}$, temperature, and concentration are used to obtain a final porosity that is between 20 and $120 \mu \mathrm{m}$. This porosity is required in order for the grafted matrix to be colonized by cells and then progressively biodegraded by host fibroblasts. The dermal portion is then sterilized.

The bilayered skin equivalent: The silicone layer of Integra is poured aseptically, in liquid form, onto the dermal layer to obtain a firm bond between the two components and to create a true "artificial skin". The dermal equivalent is then preserved in phosphate buffer and stored in crimped polyethylene pouches.

\section{Clinical cases}

Patient no. 1: Jessica P, 26 years of age, was scalded at the age of 3 . The initial burns affected $60 \%$ of the total body surface area. The burn damage occurred in areas of the abdomen, perineum, and lower limbs. The burns were initially 
treated with wound healing management and repeated grafts. Hypertrophic retractile sequelae developed after healing, most notably in the form of circular scar tissue around the abdomen and the lower back, as well as inguinal and perineal contractures. The damage to the abdomen and perineum resulted in functional problems that were the motivation of a request for corrective surgery at the age of 16 . To repair the abdomen and inguinal region, the scar tissue was excised and grafts of Integra dermal equivalent were applied (Figure 1). No recurrence of secondary scar tissue was observed. At the age of 26 , Jessica wished to have a child. Her pregnancy was uncomplicated and she had a full-term delivery of a little boy weighing $3 \mathrm{~kg}$.

Patient no. 2: Guillemette L, 28 years of age, suffered third degree burns over her entire abdominal region and the lateral sides of her trunk. During initial treatment (on the $7^{\text {th }}$ day after burn), an excision was performed and a graft of Integra dermal equivalent was applied. She did not present secondary scarring sequelae, and her abdomen remained supple after treatment. Six years later, she was able to carry a pregnancy without complications. The pregnancy resulted in a full-term delivery (Figure 2).
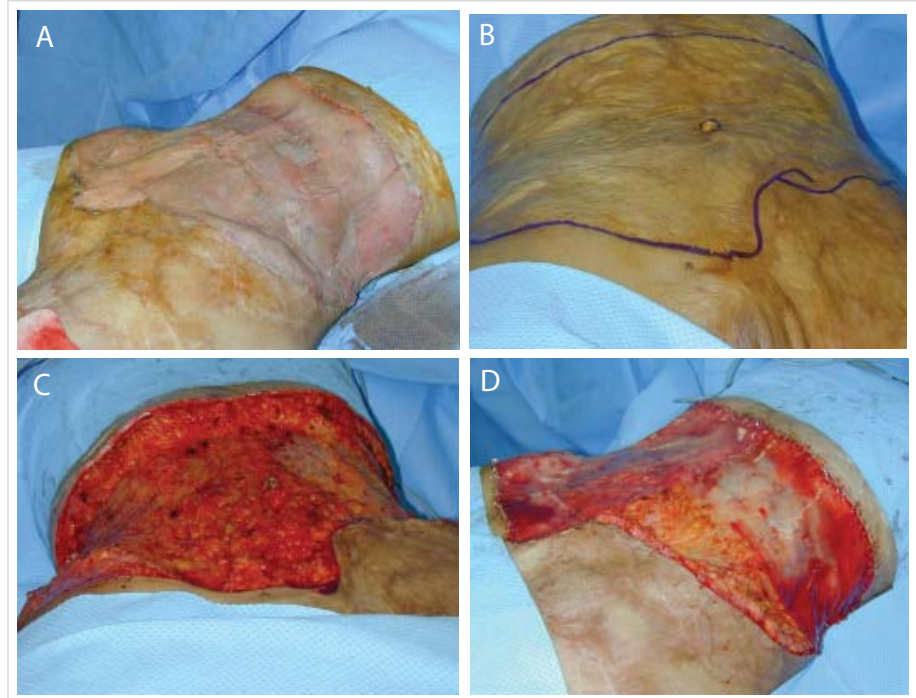

Figure 1: Surgical technique and surgical steps:

A (DSCN0007): Inelastic scars of the abdominis. B (DSCN0008): Total excsision of the scar tissue of the adbdomenis. C (DSCN0009): Immediate graft of the dermal Template Integra ${ }^{\circledR}$. D (DSCN0005): Second surgical step: Tree weeks later, when the new vascularisation is accomplished, the demal template is grafted with a thin epidermal graft.
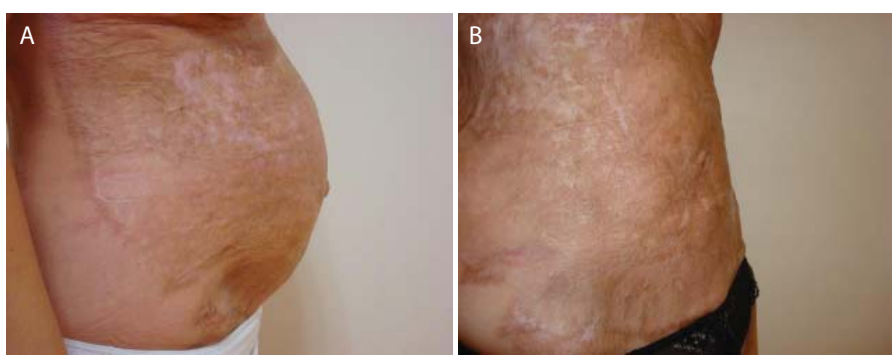

Figure 2: A (DSC08713): Clinical aspect of the grafted abdominis during pregnancy. B (DSC09626): Clinical aspect of the abdominis « 3 months after delivery.
Patient no. 3: Geraldine F, 24 years of age, was scalded at the age of 9 months. Retractile scar tissue developed over the entire trunk, leading to abdominal inelasticity, a pulling effect on the pubic region, and a lack of breast development. She wished to become pregnant and consequently was treated with surgical removal of all scar tissue on her trunk. The scar tissue was excised and replaced with a dermal equivalent graft. Two successive surgeries were performed. During the first procedure, performed, all abdominal scar tissue was removed by excision and the external genital organs were repositioned. An Integra dermal graft was applied during the same operation. Epidermization was completed 21 days later with thin epidermal grafts that were taken from the patient's two thighs. When the second surgical procedure was performed 2 months later, on July 22, all thoracic scar tissue was removed. Removal of thoracic scar tissue led to the discovery of two existing, atrophied mammary glands. Scar adherences were removed and an Integra dermal graft was applied. Again, epidermization occurred 3 weeks later. The epidermal grafts were taken from the thighs, at the same donor sites as those used for the abdomen. Having returned to her home, the patient informed us of a pregnancy that began 4 months after the first surgery. This was four months after scar removal from the trunk. The pregnancy was without complications and resulted in a full-term delivery (Figure 3).

\section{Results}

The surfaces grafted with Integra dermis were $2 \mathrm{x}$ $1250 \mathrm{~cm}^{2}$ for the first patient, $2 \times 1000 \mathrm{~cm}^{2}$ for the second patient, and $1750 \mathrm{~cm}^{2}$ for the third patient. Epidermization occurred on the 20th day after dermal grafting, during the second surgical stage for each of the three patients. We did not observe any loss of graft tissue or any complications of hematoma or infection. The long-term postoperative results have been analyzed with the Vancouver scar scale, a specific objective quantitative evaluation of the post burn scars. It assesses 4 variables: vascularity, height/thickness, pliability, and pigmentation. The Vancouver scores were 3 for the first patient and 2 for the two others ( 0 mean a normal skin, 13 for a very pathologic scar).
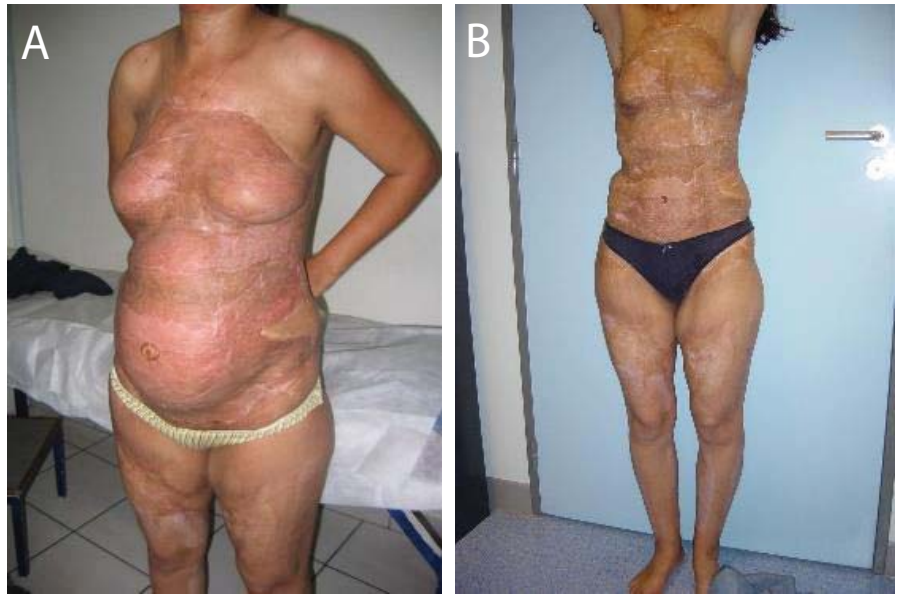

Figure 3: A (DSCN0001): Clinical aspect of the trunk during pregnancy. B (DSCN0002): Long term result 3 months after delivery. 
Excisionofthethoracicscartissuein the firstpatientrevealed mammary glands that were present but atrophied. After being freed from their adherences, they were repositioned and then covered with Integra dermis. Their growth was normal throughout the pregnancy. No engorgement from lactation was observed. All three deliveries were uncomplicated, fullterm, and vaginal. Following the pregnancies, due to the skin elasticity the abdominal walls returned to their place, no ptosis and, no diastasis were observed. The Vancouver scores remained 3 and 2, thanks to the suppleness of the skin that had been achieved. After pregnancy, the breasts of the first patient retained a normal shape and volume. Only the areolas are absent and will need to be reconstructed (Figures 4,5).

\section{Discussion}

Abdominal scar sequelae can be unproblematic during a pregnancy [13], when scar tissue is limited [15]. But also when a total skin graft of the abdomen was performed during the initial treatment $[10,12]$. Without surgery, the most common complications encountered are abdominal inelasticity and pain during the third trimester of the pregnancy $[6,9,14,16]$. Abdominal inelasticity may cause the uterus to ascend, resulting in compression of the diaphragm and dyspnea [5]. The consequences of abdominal inelasticity can be very serious if inelasticity provokes premature labor or needs to be surgically released. When releasing incisions

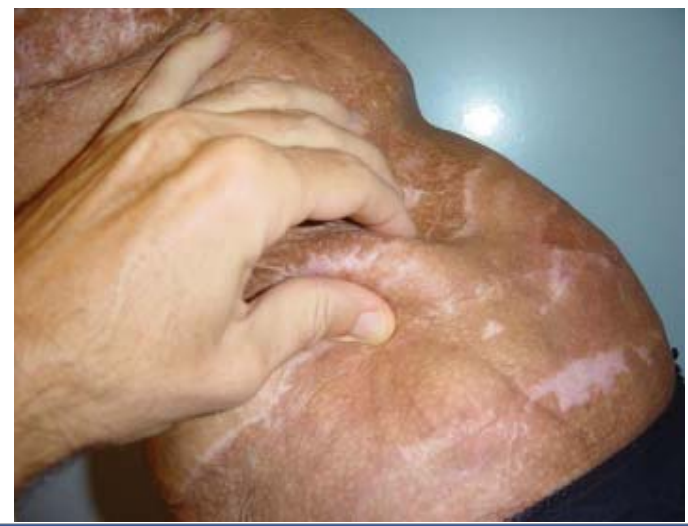

Figure 4: (DSCN 0003): Long term result 3 months after delivery (Final elasticity of the skin).

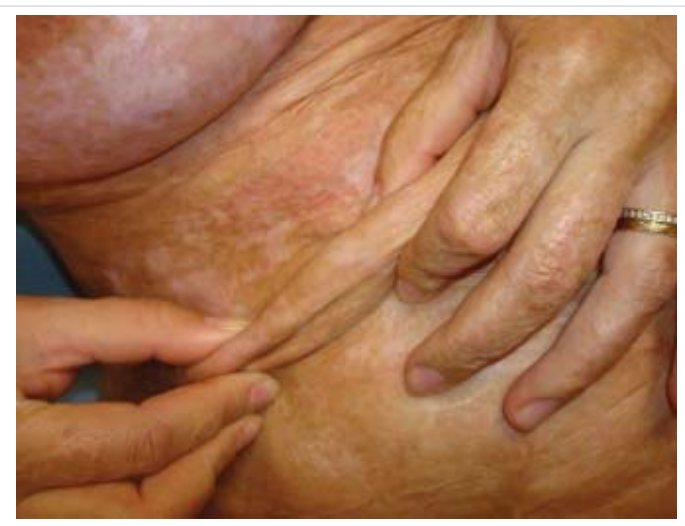

Figure 5: The final flexibility and elasticity of the abdominal skin obtained after Integra ${ }^{\circledR}$ graft. are performed to address abdominal compartment syndrome, there is an associated risk of fetal demise [6]. When a patient with large, inelastic abdominal scar tissue wishes to become pregnant, and total skin grafts or grafts of skin flaps [11] cannot be performed, dermal equivalents may be called upon. These dermal equivalents are regularly used during acute surgery of burns [1] and during corrective surgery [2,3]. Their action results in better surgical outcomes because it prevents the development of large, inelastic scar tissues, and allows for the correction of already developed scars. Since large grafts of artificial dermis are immediately available, it is possible to consider treating large surfaces like the abdomen. Consequently, when caring for the three patients subject of this series, it was possible to preventively treat scarring complications, by performing a dermal graft at the initial stage of the burn for one of the patients, and by correcting the large areas of scar tissues for the other two patients.

Of particular note is the case of the 24-year old patient who had a procedure to reposition the external genital organs that were pulled upward by scar tissue in the abdominal and pubic regions, and the inguinal folds. An uncomplicated, vaginal delivery was possible because of this correction. All of the scars on the abdomen, and those resulting from the movement of the external genital organs, were able to be treated in a single surgery, without the need for an additional skin graft [14]. This was important in this case because the clinical state of the patient did not permit the implementation of the latter technique, due to the absence of local skin graft or flap donor sites.

\section{Conclusion}

Artificial dermis has undeniable benefits because it is simple to use and can be applied to treat large surfaces, at the initial surgical stage of burn care or during the treatment of sequelae. It has, furthermore, enabled physicians to improve their patients' quality of life, when faced with the question that is asked when treating severely burned patients: "You saved their life, but what kind of life have you given them?" Restoring the skin's elasticity and suppleness allows the patient to recover normal functionality in all of life's aspects, including pregnancy. It can also be said that contributing to restoring function is a step on the road towards restoring aesthetic appearance. Therefore, dermal equivalents can truly be considered an additional technical alternative for the surgeon's arsenal. The use of this type of dermis, in its "single layer" (IDRT-SL Thin) form, reduces the number of surgeries and should thus further improve the care of these patients by reducing the number of procedures that they must undergo.

\section{References}

1. Burke JF, Yannas IV, Quinby WC, Jr., Bondoc CC, Jung WK Successful use of a physiologically acceptable artificial skin in the treatment of extensive burn injury. Ann Surg. 1981; 194: 413-428. PubMed: https://www.ncbi.nlm.nih.gov/pmc/articles/PMC1345315/ 
2. Dantzer E, Queruel P, Salinier L, Palmier B, Quinot JF. Integra, a new surgical alternative for the treatment of massive burns. Clinical evaluation of acute and reconstructive surgery: 39 cases. Ann Chir Plast Esthet. 2001; 46: 173-189.

PubMed: https://www.ncbi.nlm.nih.gov/pubmed/11447623

3. Dantzer E, Braye FM. Reconstructive surgery using an artificial dermis (Integra): results with 39 grafts.Br J Plast Surg. $2001 ; 54$ : 659-664. PubMed : https://www.ncbi.nlm.nih.gov/pubmed/11728107

4. Daw E, Mohandas I. Pregnancy in patients after severe abdominal burns. British Journal of obstetrics and gynecology. 1983; 90: 69-72. PubMed: https://www.ncbi.nlm.nih.gov/pubmed/6821672

5. Fioretti $P$, Weiss $C$, Cilotti $A$, Strigini $F$, Melis GB. Old abdominal burns and caesarean section case report. Bri J Obstets Gynecol. 1987; 99: 596-597.

PubMed: https://www.ncbi.nlm.nih.gov/pubmed/3620406

6. Haesker B,Green MF. A complication in pregnancy due to severe burns in childhood. Br J Plast Surg. 1981; 34: 102-104.

PubMed: https://www.ncbi.nlm.nih.gov/pubmed/7459514

7. Heimbach D, Luterman A, Burke J, Cram A, Herndon D, Hunt J, et al. Artificial dermis for major burns. A multi-center randomized clinical trial. Ann Surg. 1988; 208: 313-320.

PubMed: https://www.ncbi.nlm.nih.gov/pmc/articles/PMC1493652/

8. Heimbach DM, Warden GD, Luterman A, Jordan MH, Ozobia N, et al. Multicenter postapproval clinical trial of Integra dermal regeneration template for burn treatment. J Burn Care Rehabil .2003; 24: 42-48. PubMed: https://www.ncbi.nlm.nih.gov/pubmed/12543990

9. Ivy ME, Possenti PP, Kepros J, Atweh NA, D'Aiuto M, et al. Abdominal comportment syndrome in patients with burns. J Burn Care Rehabil. 1999; 20: 351-353.

PubMed: https://www.ncbi.nlm.nih.gov/pubmed/10501319

10. Kitzmiller WJ,Neale HW,Warden GD.The effects of full thickness abdominal wall burns sustained during childhood of subsequent childbearing ability. Ann Plast Surg. 1998; 40: 111-113.

PubMed: https://www.ncbi.nlm.nih.gov/pubmed/9495456

11. Lin SD, Chou CK, Yang CC, Lai CS. Management of hypertrophic scars on the pubic area with an iliac flap. Burns. 1991; 7: 220-224. PubMed: https://www.ncbi.nlm.nih.gov/pubmed/1892555

12. Mac Cawley RL,Sternberg BA,Phillips LG and All. Long term assessment of the effects of circumferential truncal burns in peadiatric patients on subsequents pregnancies. J Burn Care Rehabil. 1991; 12: 51-53. PubMed: https://www.ncbi.nlm.nih.gov/pubmed/2022682

13. Webb JC, Baack BR, Osler TM, Davis VH, Izquierdo LA, et al. A pregnancy complicated by mature abdominal burn scarring and its surgical solution: case report. J Burn Care Rehabil. 1995; 16: 276-279. PubMed: https://www.ncbi.nlm.nih.gov/pubmed/7673308

14. Widgerow $A D$, Ford TD, Botha M. Burn contracture preventing uterine expansion. Ann Plast Surg, 1991; 27: 269-271.

PubMed: https://www.ncbi.nlm.nih.gov/pubmed/1835337 